African Crop Science Journal by African Crop Science Society is licensed under a Creative Commons Attribution 3.0 Uganda License. Based on a work at www.ajol.info/ and www.bioline.org.br/cs DOI: https://dx.doi.org/10.4314/acsj.v28i2.9

\title{
ALLELIC VARIATIONS IN AROMA GENE IN CULTIVATED RICE VARIETIES
}

\author{
A. AKWERO ${ }^{1}$, D. OCAN ${ }^{1,2}$, W. AKECH ${ }^{1}$, J. LAMO ${ }^{3}$, M. OCHWO-SSEMAKULA ${ }^{1}$ \\ and P. RUBAIHAYO
}

\begin{abstract}
${ }^{1}$ Makerere University, College of Agriculture and Environmental Sciences, School of Agricultural Sciences, Department of Agricultural Production, P. O. Box 7062, Kampala, Uganda

${ }^{2}$ Gulu University, Faculty of Agriculture, Department of Agronomy, P. O. Box 166, Gulu, Uganda

${ }^{3}$ National Crops Resources Research Institute, Namulonge, P. O. Box 7084, Kampala, Uganda

Corresponding author: akwero@gmail.com
\end{abstract}

(Received 2 April 2020; accepted 23 June 2020)

\begin{abstract}
Germplasm is a valuable source of genetic diversity that supports crop improvement efforts in any breeding programme but it must first be fully characterised for economically valuable traits before it can be effectively utilised. In rice (Oryza sativa), the development of new varieties with improved aroma requires correct phenotyping and prior knowledge of the available genes and alleles governing the aroma trait in the gene pool. Correct phenotyping and genotyping can be achieved using sensory methods and functional markers associated with polymorphisms that define the aroma genes. The objective of this study was to evaluate the aroma status of rice accessions and to assess for the various alleles of $b a d h 2$ gene using functional markers. A total of 56 rice accessions were evaluated at National Crops Resources Research Institute (NaCRRI) in Uganda for their aroma using sensory methods and a molecular marker to differentiate between aromatic and non- aromatic accessions. The aromatic accessions were then evaluated for variations within the betaine aldehyde dehydrogenase 2 (badh2) gene responsible for aroma in rice using functional markers. Sensory evaluation of aroma identified 23 accessions to be aromatic; while 33 were non-aromatic. Molecular results identified 20 accessions as aromatic; while 36 accessions were non-aromatic. Functional marker analysis indicated the presence of badh2-E7 allele in 20 aromatic accessions within this collection that could be employed in the breeding programme for the rice aromatic trait.
\end{abstract}

Key Words: badh2 alleles, functional markers, Oryza sativa

\section{RÉSUMÉ}

Le germoplasme est une source précieuse de diversité génétique qui soutient les efforts d'amélioration des cultures dans tout programme de sélection, mais il doit d'abord être entièrement caractérisé pour ses traits économiquement précieux avant de pouvoir être utilisé efficacement. Dans le riz (Oryza sativa), le développement de nouvelles variétés avec un arôme amélioré nécessite un phénotypage correct et une connaissance préalable des gènes et allèles disponibles régissant le caractère aromatique 
dans le pool génétique. Un phénotypage et un génotypage corrects peuvent être obtenus en utilisant des méthodes sensorielles et des marqueurs fonctionnels associés à des polymorphismes qui définissent les gènes aromatiques. L'objectif de cette étude était d'évaluer le statut aromatique des accessions de riz et d'évaluer les différents allèles du gène badh2 à l'aide de marqueurs fonctionnels. Un total de 56 accessions de riz ont été évaluées au National Crops Resources Research Institute (NaCRRI) en Ouganda pour leur arôme en utilisant des méthodes sensorielles et un marqueur moléculaire pour différencier les accessions aromatiques et non aromatiques. Les accessions aromatiques ont ensuite été évaluées pour les variations au sein du gène de la bétaine aldéhyde déshydrogénase 2 (badh2) responsable de l' arôme du riz à l'aide de marqueurs fonctionnels. L'évaluation sensorielle de l'arôme a identifié 23 accessions comme aromatiques; tandis que 33 étaient non aromatiques. Les résultats moléculaires ont identifié 20 accessions comme aromatiques; tandis que 36 accessions n'étaient pas aromatiques. L'analyse des marqueurs fonctionnels a indiqué la présence d'allèles badh2$E 7$ dans 20 accessions aromatiques de cette collection qui pourraient être utilisées dans le programme de sélection pour le trait aromatique du riz.

Mots Clés: badh2 alleles, Marqueurs fonctionnels, Oryza sativa

\section{INTRODUCTION}

Rice (Oryza sativa L.) is a staple crop and major source of income for many farmers in sub-Saharan Africa. Aromatic rice is preferred by consumers compared to non-aromatic rice (Asante, 2017) and it fetches a premium price, both locally and internationally (Calingacion $e t$ al., 2014; Diagne et al., 2017). Production of aromatic rice in Uganda is far below the market demand, hence traders have resorted to the adulteration of aromatic rice with nonaromatic rice so as to maximise profits (Vemireddy et al., 2015). Given the increasing demand for aromatic rice, the proportion of imported aromatic rice is likely to increase unless local production of aromatic rice is increased (Masette et al., 2013). Breeding rice varieties with enhanced aroma by introducing aroma into non-aromatic elite varieties that are already well adapted by farmers, will augment the production of aromatic rice in Uganda.

Conventional breeding methods combined with selection of DNA markers, so called Marker Assisted Selection (MAS), is a fast and efficient strategy for the introgression of aroma trait (Golestan Hashemi et al., 2015). But this requires correct phenotyping of the breeding materials for aroma and understanding the genetic basis of aroma in these materials.
Aromatic rice emits a popcorn-like aroma from the leaves, grains and flowering organs at various stages of growth (Hinge et al., 2016). Three approaches are commonly used by researchers to determine the presence or absence of aroma in rice. Firstly, sensory evaluation of aroma from leaves or grains using dilute KOH (Sood and Siddq, 1978). The sensory test for aroma from leaf tissue or grain after reacting with $\mathrm{KOH}$ is a cheap, convenient, rapid and reliable method for identification of aromatic and non-aromatic genotypes by breeding programmes (Yeap et al., 2013).

Secondly, analysis of aroma in the grain using gas chromatography by measuring the amount of 2-Acetyl-1-Pyrroline (2AP), a compound that is responsible for aroma (Maravel et al., 2010; Daygon et al., 2017; Ocan et al., 2019). Finally, using DNA markers linked to aroma trait and Functional markers that target the polymorphism that define the functional and non-functional alleles of the aroma gene (Bradbury et al., 2005b). Functional markers provide a more efficient selection of desired genotypes compared to DNA markers located nearby but at functionally irrelevant site (Andersen and Lübberstedt, 2003). Functional markers are diagnostic of the desired trait allele (Varshney et al., 2005) 
and can be used for validation of cultivar identity, selection of parental materials to build segregation populations and subsequent selection of lines (Lübberstedt et al., 2005).

Aroma in rice is caused by loss of function of the Betaine Aldehyde Dehydrogenase2 (BADH2) enzyme that is coded by the badh2 gene found on Chromosome 8 (Bradbury et al., 2005b). Loss of function of BADH2 enzyme leads to accumulation of 2AP. The badh2 gene has 15 exons and 14 introns and mutations within this gene have been associated with the accumulation of $2 \mathrm{AP}$ which determines the aroma of rice (Table 1).

Initially an eight base pair (bp) deletion and a three Single Nucleotide Polymorphism (SNP) was found in exon 7 and named the badh2-E7 allele (Bradbury et al., 2005a). Evidence of the existence of additional mutations within the badh2 gene was found in a study of several accessions from Asia that had elevated levels of 2AP, but did not carry the badh2-E7 allele (Fitzgerald et al., 2008), implying the existence of other alleles. A seven bp deletion in exon 2 was discovered (Shi et al., 2008) and eight other mutations were also found to be associated with fragrance (Kovach et al., 2009). An 803-bp deletion between exons 4 and 5 (designated as badh2.E4-5) was later discovered (Shao et al., 2011). Another new allele (badh2-p-5'UTR) that has a 3-bp deletion in the 5 'untranslated region (UTR) and an 8bp insertion in the promoter $(-1,314$ site upstream from the initiation codon) was also discovered by Shi et al. (2014). In addition, 3bp deletion in exon 12 and an 8bp insertion in the promoter region of the badh2 gene have also been associated with fragrance (He et al., 2015; Bindusree et al., 2017). Nineteen alleles of badh2 gene have so far been reported, which account for the unique spectrum of fragrance found in aromatic rice varieties.

There is a wide collection of rice germplasm that have been introduced from various rice breeding centers around the world and are currently held at the National Crops Resources

TABLE 1 . Summary of badh2 alleles reported to be associated with aroma in rice

\begin{tabular}{|c|c|c|c|}
\hline Alleles & Location & Sequence Divergence & Reference \\
\hline badh2-E7 & Exon 7 & 8bp deletion & Bradbury et al. (2005a) \\
\hline badh2-E8 & Exon 8 & $7 \mathrm{bp}$ insertion & Amarawathi et al. (2007) \\
\hline badh2-E2.1 & Exon 2 & $7 \mathrm{bp}$ deletion & Shi et al. (2008) \\
\hline badh2-E1.1 & Exon 1 & $2 \mathrm{bp}$ deletion & Kovach et al. (2009) \\
\hline badh2-E10.1 & Exon 10 & 1bp insertion & Kovach et al. (2009) \\
\hline badh2-E10.2 & Exon 10 & 1bp deletion & Kovach et al. (2009) \\
\hline badh2-E10.3 & Exon 10 & G/T SNP & Kovach et al. (2009) \\
\hline badh2-E13.1 & Exon 13 & 3bp insertion & Kovach et al. (2009) \\
\hline badh2-E13.2 & Exon 13 & C/T SNP & Kovach et al. (2009) \\
\hline badh2-E14.1 & Exon 14 & 1bp insertion & Kovach et al. (2009) \\
\hline badh2-E14.2 & Exon 14 & G/T SNP & Kovach et al. (2009) \\
\hline badh2-E4-5.2 & Exon $4-5$ & 803bp deletion & Shao et al. (2011) \\
\hline badh2-E4-5.1 & Exon $4-5$ & 806bp deletion & Shao et al. (2013) \\
\hline badh2-E2.2 & Exon 2 & $75 b p$ deletion & Shao et al. (2013) \\
\hline badh2-E10.4 & Exon 10 & G/A SNP & Shao et al. (2013) \\
\hline badh2-p-5'UTR & 5'UTR & 3bp deletion & Shi et al. (2014) \\
\hline badh2-E1.2 & Exon 1 -intron 1 junction & G/A SNP & Ootsuka et al. (2014) \\
\hline badh2-E12 & Exon 12 & 3bp deletion & He and Park (2015) \\
\hline badh2-p & Promoter region & 8 bp insertion & Bindusree et al. (2017) \\
\hline
\end{tabular}


Research Institute (NaCRRI) in Uganda to support aromatic rice-breeding efforts. However, utilisation of this germplasm for rice improvement is constrained by limited knowledge of the phenotypic and genotypic diversity within this collection. For a breeding programme to be successful, it is important to have prior knowledge of the phenotypic and genotypic characteristics of important traits in the available germplasm. Attempts have been made to assess the aroma panel of some accessions using sensory methods and gas chromatography (Kanaabi et al., 2018; Ocan et al., 2019), but the genetic basis of aroma in these and other accessions have not been comprehensively established. The objective of this study was thus to evaluate the aroma status of 56 rice accessions and to assess for the various alleles of badh2 gene using functional markers.

\section{MATERIALS AND METHODS}

Source of rice germplasm. The study was based on a collection of 56 rice accessions which includes upland and lowland rice of $O$. glaberrima, $O$. sativa and interspecific crosses between $O$. sativa and $O$. barthii acquired from the National Crops Resources Research Institute, Namulonge (NaCRRI-Uganda) (Table 2).

Experimental setup. Individual rice accessions were planted in 15 liter capacity pots with nine plants per pot in a complete randomised design at NaCRRI in Uganda. At two weeks post emergence, one leaf per plant was picked from all nine plants and stored at $80{ }^{\circ} \mathrm{C}$ for further analysis.

Assessment of aroma using sensory method. The presence or absence of aroma was determined by sensory testing using the procedure of Sood and Siddiq (1978). Fresh leaf samples $(10 \mathrm{~g})$ of rice plants at tillering growth stage were obtained and cut into $3 \mathrm{~mm}$ pieces using a pair of scissor; and placed in a ventilation vial containing $10 \mathrm{ml}$ of $1.7 \% \mathrm{KOH}$ and, thereafter, incubated at room temperature $\left(27^{\circ} \mathrm{C}\right)$ for 10 minutes. The samples were then smelled and rated one at a time for aroma by a panel of six evaluators, who were selected based on their experience as technicians with the rice breeding programme at NaCRRI and their ability to distinguish aromatic rice from non-aromatic rice, using blind samples. The evaluation of aroma was done on a scale of 13 , where 1 was non-aromatic, 2 slightly aromatic and 3 highly aromatic (IRRI, 2013). The order of scoring of 56 accessions was randomised within each individual panelist.

Assessment of aroma and allele diversity using functional markers. Genomic DNA was extracted from the young leaves that were earlier collected and stored at $-80{ }^{\circ} \mathrm{C}$, using the CTAB method (Doyle, 1991) with minor modifications. The modification included addition of ice cold isopropanol to the aqueous layer and mixed thoroughly. This was incubated at $-20^{\circ} \mathrm{C}$ for 30 minutes, then added $10 \mathrm{mM}$ ammonium acetate and incubated for another 30 minutes at $-20^{\circ} \mathrm{C}$ before spinning at $13000 \mathrm{rpm}$ for 10 minutes to precipitate the DNA).

The quality of DNA was checked using a ND-1000 NanoDrop spectrophotometer (Thermo Fisher Scientific, Waltham, Massachusettes, USA). Polymerase chain reactions (PCR) amplifications were performed using five primers (Table 3) in ArkTik thermal Cycler (Thermal Scientific, Finland). Each reaction contained $5 \mu \mathrm{l}$ of AccuPower PCR Premix (Bioneer, Daejeon, Korea), $1 \mu \mathrm{M}$ of each primer and $50 \mathrm{ng}$ of template DNA. The final reaction volume was completed to $10 \mu \mathrm{l}$ using sterile distilled water.

For the ASA (ESP, EAP, INT, IFAP, and ISP) the reaction was programmed for an initial 5 min cycle at $95{ }^{\circ} \mathrm{C}$; followed by 35 cycles of $30 \mathrm{~s}$ at $95{ }^{\circ} \mathrm{C}, 40 \mathrm{~s}$ at $55^{\circ} \mathrm{C}$, and 1 min at $72{ }^{\circ} \mathrm{C}$; with a final extension of $5 \mathrm{~min}$ at $72{ }^{\circ} \mathrm{C}$. For the rest of primers, the cycling conditions followed a touch-down programme 
TABLE 2. Description of genotypes used in the study

\begin{tabular}{|c|c|c|c|c|c|c|c|c|c|}
\hline Entry no & $\begin{array}{l}\text { Name } \\
\text { Pedigree }\end{array}$ & Origin & Ecology & Species & Entry no & $\begin{array}{l}\text { Name/ } \\
\text { Pedigree }\end{array}$ & Origin & Ecology & Species \\
\hline 1 & Tog5674 & ARC & Upland & Glaberrima & 29 & SUPA6 & IRRI & Lowland & Sativa/indica \\
\hline 2 & Tog5672 & ARC & Upland & Glaberrima & 30 & Gigante & IRRI & Lowland & Sativa/indica \\
\hline 3 & Tog5681 & $\mathrm{ARC}$ & Upland & Glaberrima & 31 & Komboka & IRRI & Lowland & Sativa/ indica \\
\hline 4 & MET3 & ARC & Upland & ISC: O.S x O. B & 32 & Basmati370 & IRRI & Lowland & Sativa/ indica \\
\hline 5 & MET 4 & $\mathrm{ARC}$ & Upland & ISC: O.S x O. B & 33 & WITA9 & IRRI & Lowland & Sativa/indica \\
\hline 6 & MET 6 & $\mathrm{ARC}$ & Upland & ISC: O.S x O. B & 34 & Supa Local & NaCRRI & Lowland & Sativa/indica \\
\hline 7 & MET12 & ARC & Upland & ISC: O.S x O. B & 35 & AGRA41 & unknown & Upland & Sativa/japonica \\
\hline 8 & MET 13 & ARC & Upland & ISC: O.S x O. B & 36 & AGRA60 & unknown & Upland & Sativa/japonica \\
\hline 9 & MET14 & ARC & Upland & ISC: O.S x O. B & 37 & AGRA65 & unknown & Upland & Sativa/japonica \\
\hline 10 & MET15 & $\mathrm{ARC}$ & Upland & ISC: O.S x O. B & 38 & NamChe1 & NaCRRI & Upland & Sativa/japonica \\
\hline 11 & MET16 & ARC & Upland & ISC: O.S x O. B & 39 & NamChe2 & NaCRRI & Upland & Sativa/japonica \\
\hline 12 & MET30 & $\mathrm{ARC}$ & Upland & ISC: O.S x O. B & 40 & NamChe3 & NaCRRI & Upland & Sativa/japonica \\
\hline 13 & MET40 & $\mathrm{ARC}$ & Upland & ISC: O.S x O. B & 41 & NamChe4 & NaCRRI & Upland & Sativa/japonica \\
\hline 14 & MET60 & ARC & Upland & ISC: O.S x O. B & 42 & NamChe5 & NaCRRI & Upland & Sativa/japonica \\
\hline 15 & MET70 & ARC & Upland & ISC: O.S x O. B & 43 & NamChe6 & NaCRRI & Upland & Sativa/japonica \\
\hline 16 & $\mathrm{ARC} 1$ & ARC & Lowland & Sativa/indica & 44 & E20 & NaCRRI & Upland & Sativa/japonica \\
\hline 17 & ARC2 & $\mathrm{ARC}$ & Lowland & Sativa/indica & 45 & E22 & NaCRRI & Upland & Sativa/japonica \\
\hline 18 & ARC3 & ARC & Lowland & Sativa/indica & 46 & NERICA1 & $\mathrm{ARC}$ & Upland & Sativa/japonica \\
\hline 19 & ARC4 & $\mathrm{ARC}$ & Lowland & Sativa/indica & 47 & NERICA4 & ARC & Upland & Sativa japonica \\
\hline 20 & ARC5 & $\mathrm{ARC}$ & Lowland & Sativa/indica & 48 & NERICA8 & ARC & Upland & Sativa japonica \\
\hline 21 & ARS11 & ARC & Lowland & Sativa/indica & 49 & NERICA10 & ARC & Upland & Sativa/japonica \\
\hline 22 & IR64 & IRRI & Lowland & Sativa/indica & 50 & 1189 line & ARC & Upland & Sativa/japonica \\
\hline 23 & SUPA1052 & IRRI & Lowland & Sativa/indica & 51 & 1190 line & ARC & Upland & Sativa/japonica \\
\hline 24 & SUPA1 & IRRI & Lowland & Sativa/indica & 52 & 1191 line & ARC & Upland & Sativa/japonica \\
\hline 25 & SUPA2 & IRRI & Lowland & Sativa/indica & 53 & 326104 line & KOREA & Lowland & Sativa/indica \\
\hline 26 & SUPA3 & IRRI & Lowland & Sativa/indica & 54 & Sande & $\mathrm{TZ}$ & Lowland & Sativa/indica \\
\hline 27 & SUPA4 & IRRI & Lowland & Sativa/ indica & 55 & TXD306 & $\mathrm{TZ}$ & Lowland & Sativa/indica \\
\hline 28 & SUPA5 & IRRI & Lowland & Sativa/indica & 56 & Jaribu & $\mathrm{TZ}$ & Lowland & Sativa/indica \\
\hline
\end{tabular}

Africa Rice Center (ARC), International Rice Research Institute (IRRI), Tanzania (TZ), National Crops Resources Research Institute (NaCRRI), Interspecific Cross between Oryza sativa and Oryza barthii (ISC: O.S x O.B) 
TABLE 3. Primers for the analysis of aroma and the allelic variations in badh2 gene in rice

\begin{tabular}{|c|c|c|c|}
\hline Primer name & Primer sequence $\left(5^{\prime}->3^{\prime}\right)$ & PCR Product Size & Source \\
\hline FMBADH2-E2A & $\begin{array}{l}\text { F: CCTCTGCTTCTGCCTCTGAT } \\
\text { R:GATTGCGCGGAGGTACTTG }\end{array}$ & $\begin{array}{l}\text { 200/207bp } \\
\text { (badh2-E2/badh2) }\end{array}$ & Shi et al. (2008) \\
\hline FMBADH2-E2B & $\begin{array}{l}\text { F: CTTCTGCCTCTGATTAGCCT } \\
\text { R: GCCGTGAGCCATATACACTT }\end{array}$ & $\begin{array}{l}\text { 643/650bp } \\
\text { (badh2-E2/badh2) }\end{array}$ & Shi et al. (2008) \\
\hline FMBADH2-E7 & $\begin{array}{l}\text { F: GGTTGCATTTACTGGGAGTT } \\
\text { R:CAGTGAAACAGGCTGTCAAG }\end{array}$ & $\begin{array}{l}\text { 260/268 bp } \\
(\text { badh2-E7/badh2) }\end{array}$ & Shi et al. (2008) \\
\hline FMBADH2-E-4-5 & $\begin{array}{l}\text { F:TGCTGGATGCTTTGAGTA } \\
\text { R:GTTTAGACACCTGAAGGAAGACCA }\end{array}$ & $\begin{array}{l}321 / 1123 \mathrm{bp} \\
\text { (badh2-E4-5/badh2) }\end{array}$ & Shao et al. (2011) \\
\hline *External Sense Primer (ESP) & TTGTTTGGAGCTTGCTGATG & $580 \mathrm{bp}$ & \\
\hline External Antisense Primer (EAP) & AGTGCTTTACAAAGTCCCGC & & Bradbury et al. (2005a) \\
\hline *Internal Fragrant Antisense Primer (IFAP) & CATAGGAGCAGCTGAAATATATACC & $257 / 355 b p$ & \\
\hline Internal Non-fragrant Sense Primer (INSP) & CTGGTAAAAAGATTATGGCTTCA & (Aromatic/Non-aromatic) & Bradbury et al. (2005a) \\
\hline
\end{tabular}

*ESP, EAP, IFAP and INSP are multiplexed in a single PCR tube for amplification and named Allele Specific Assay (ASA) hereafter. ASA and FMBADH2E7 were designed to track the 8bp deletion and 3SNP on exon 7

FMBADH2-E2A and FMBADH2-E2B were designed to track the 7bp deletion on exon 2 while FMBADH2-E4-5 was designed to track the 803 bp deletion between exons 4 and 5 
starting at an annealing temperature of $64^{\circ} \mathrm{C}$ with $1{ }^{\circ} \mathrm{C}$ reduction in every cycle gradually until $56^{\circ} \mathrm{C}$ (eight cycles) and then maintained at a constant annealing temperature of $56^{\circ} \mathrm{C}$ for the remaining 27 cycles. The reaction was, thus programmed for an initial 5 min cycle at $95{ }^{\circ} \mathrm{C}$. This was followed by 8 cycles of $30 \mathrm{~s}$ at $95{ }^{\circ} \mathrm{C}, 40 \mathrm{~s}$ at $64{ }^{\circ} \mathrm{C}-56{ }^{\circ} \mathrm{C}$, and $1 \mathrm{~min}$ at $72{ }^{\circ} \mathrm{C}$; followed by 27 cycles at similar conditions, except for annealing temperature maintained at $56{ }^{\circ} \mathrm{C}$ with a final extension of 5 min at $72{ }^{\circ} \mathrm{C}$.

All PCR products were segregated on a $1.2 \%(\mathrm{w} / \mathrm{v})$ agarose gel, except for primers FMBADH2-E2A and FMBADH2-E7 which were segregated on $3 \%(\mathrm{w} / \mathrm{v})$ agarose gel. All gel were prepared in $1 \mathrm{XTBE}$ buffer and stained with EZ (0.8 $\left.\mathrm{ug}^{-1} \mathrm{~mL}\right)$ (AMRESCO, Ohio, USA) and visualised using a BioDoc-It Imaging System (Thermo Fisher Scientific, Waltham, Massachusettes, USA). A 100 bp ladder (Bioneer, Daejeon, Korea) was used to estimate the PCR fragment sizes.

PCR products were then shipped to Macrogen Laboratory in the Netherlands for sequencing. PCR products were sequenced in the reverse direction using primers EAP, FMBADH2-E2A(R) and FMBADH2-E7(R). Each fragment was sequenced at least four times and high quality consensus sequences were used for data analysis.

Data analyses. Both descriptive and inferential data analyses were performed using R Statistical software (R Core Team 2017) and Microsoft excel (MS Excel 2017). Frequencies were generated using Excel. Friedman Sum Rank Test (Hollander and Wolfe, 1973) was used to determine differences in sensory scores among the 56 genotypes.

To determine whether a given genotype was aromatic or not, a Friedman Sum rank test was performed using a median score from the six evaluators while taking each individual assessor as a block.

To test for association between aroma and badh2 alleles, Chi-square test of association was performed. Sequences were manually edited and aligned using Clustal W and MEGA7: Molecular Evolutionary Genetics Analysis version 7.0 for bigger datasets (Kumar et al. 2016). Multiple sequence alignment was done to identify the presence of deletions and SNPs in the lines.

\section{RESULTS}

Sensory analysis for aroma. Friedman Sum Rank test showed significant (Friedman chisquared $=229.82$, df $=55$ P-value $<2.2 \mathrm{x}$ $10^{-16}$ ) differences in sensory scores among the 56 genotypes (Table 4). Out of the 56 accessions, 23 were classified as aromatic by at least one evaluator; and 33 classified as nonaromatic based on median of sensory evaluation scores. Out of the 23 aromatic accessions, nine accessions were classified as highly aromatic and 14 classified as moderately aromatic (Table 4).

Sensory evaluation revealed 23 accessions to be aromatic ( 9 highly aromatic, plus 14 moderately aromatic) and 33 accessions were non-aromatic; thus grouping the accessions according to the strength of aroma emitted. MET40, SUPA1, SUPA5, AGRA41, AGRA60, MET16, MET3, MET4 and MET13 were highly aromatic (Median Score >2) while Basmati370, Komboka, SUPA6, Jaribu, MET12, MET14, MET15, MET6, NamChe1, Namche5, Sande, SUPA1052, SUPA2, and Supa Local were moderately aromatic (median Score ranging from 1 to 2 ).

Considering the ecology of the rice accessions, 13 upland accessions were aromatic while 20 were non-aromatic. Similarly, 10 lowland accessions were aromatic; while 13 were non-aromatic. A Chisquare test of association between aroma and ecology (upland or lowland) was not significant (Chi-square: 0.0543, P-value: 3.841)

Aroma and allelic variations in the badh2

gene. Molecular marker analysis was used to validate the aroma status of rice accessions obtained in the previous section (sensory 


\section{A. AKWERO et al.}

analysis of aroma) and to determine the allelic variations within the aroma gene in the accessions (Table 5).

Functional Marker ASA revealed that 21 accessions were aromatic, and thus carry the badh2-E7 allele of which three were heterozygous aromatic as they carried both the functional and non functional alleles. FMBADH2-E7 revealed only 19 accessions to be aromatic, and thus carry the badh2-E7 allele; but two accessions (SUPA1 and Jaribu) which were initially scored as aromatic using the sensory method and found to be nonaromatic because they did not carry the badh2E7 allele. Similarly, three accessions (NamChe1, NamChe5 and MET14) were initially scored as aromatic using sensory test but both the ASA and FMBADH2-E7 functional marker indicated that they were non-aromatic and thus did not carry the badh2-E7 allele. In another twist, one accession (AGRA65) was found to be aromatic using ASA and FMBADH2-E7 molecular markers and thus carrying the eight bp deletion yet it was initially scored as non-aromatic, using sensory analysis. Sequencing results confirmed the presence of an eight bp deletion and three SNPs in AGRA65; and the absence of the eight bp deletion in SUPA1, Jaribu, NamChe1, NamChe5 and MET14.(Fig. 1).

The functional markers FMBADH2.E2A and FMBADH2.E2B designed to detect the seven bp deletion on exon two, designated as the badh2-E2 allele, gave inconsistent results. Using FMBADH2.E2A, non aromatic accession was found to contain the badh2-E2 allele. Surprisingly, four non-aromatic accessions (ARC3, E20, Tog5672 and TXD306) were positive for the badh2-E2 allele. Functional marker FMBADH2-E2A, therefore, gave contradicting results indicating that four accessions were aromatic yet the sensory test indicated that they were not. FMBADH2-E2B identified nine accessions as aromatic and 26 accessions as non aromatic, similar to results revealed by the sensory test. In addition, 14 accessions were found to be non-aromatic contrary to the sensory test; 
TABLE 5. Validation of sensory results and determination of allelic variations in the badh2 gene using functional markers

\begin{tabular}{|c|c|c|c|c|c|c|c|}
\hline \multirow[t]{3}{*}{ Entry no. } & \multirow[t]{3}{*}{ Accession } & \multirow{3}{*}{$\begin{array}{r}\text { Aroma } \\
\text { status }\end{array}$} & \multicolumn{4}{|c|}{ Functional markers } & \multirow[b]{2}{*}{$\begin{array}{l}\text { FMBADH2 } \\
\text {-E4-5 }\end{array}$} \\
\hline & & & ASA & $\begin{array}{l}\text { FMBADH2 } \\
\text {-E7 }\end{array}$ & $\begin{array}{l}\text { FMBADH2 } \\
\text {-E2A }\end{array}$ & $\begin{array}{l}\text { FMBADH2 } \\
\text {-E2B }\end{array}$ & \\
\hline & & & $\begin{array}{c}8 \mathrm{bp} \\
\text { deletion }\end{array}$ & $\begin{array}{c}\text { 8bp } \\
\text { deletion }\end{array}$ & $\begin{array}{c}\text { 7bp } \\
\text { deletion }\end{array}$ & $\begin{array}{c}\text { 7bp } \\
\text { deletion }\end{array}$ & $\begin{array}{c}803 \\
\text { deletion }\end{array}$ \\
\hline 1 & $\operatorname{Tog} 5674$ & 1 & - & - & - & - & - \\
\hline 2 & $\operatorname{Tog} 5672$ & 1 & - & - & + & - & - \\
\hline 3 & $\operatorname{Tog} 5681$ & 1 & - & - & - & - & - \\
\hline 4 & MET3 & 3 & + & + & - & + & - \\
\hline 5 & MET 4 & 3 & + & + & - & + & - \\
\hline 6 & MET 6 & 2 & + & + & - & + & - \\
\hline 7 & MET12 & 2 & + & + & - & - & - \\
\hline 8 & MET 13 & 3 & + & + & - & - & - \\
\hline 9 & MET14 & 2 & - & - & - & - & - \\
\hline 10 & MET15 & 2 & + & + & - & + & - \\
\hline 11 & MET16 & 3 & + & + & - & + & - \\
\hline 12 & MET30 & 1 & - & - & - & - & - \\
\hline 13 & MET40 & 3 & + & + & - & - & - \\
\hline 14 & MET60 & 1 & - & - & - & + & - \\
\hline 15 & MET70 & 1 & - & - & - & - & - \\
\hline 16 & $\mathrm{ARC1}$ & 1 & - & - & - & - & - \\
\hline 17 & $\mathrm{ARC} 2$ & 1 & - & - & - & - & - \\
\hline 18 & ARC3 & 1 & - & - & + & - & - \\
\hline 19 & $\mathrm{ARC} 4$ & 1 & - & - & - & - & - \\
\hline 20 & ARC5 & 1 & - & - & - & - & - \\
\hline 21 & ARS11 & 1 & - & - & - & - & - \\
\hline 22 & IR64 & 1 & - & - & - & - & - \\
\hline 23 & SUPA1052 & 2 & + & + & - & - & - \\
\hline 24 & SUPA1 & 3 & + & - & - & - & - \\
\hline 25 & SUPA2 & 2 & + & + & - & - & - \\
\hline 26 & SUPA3 & 1 & - & - & - & - & - \\
\hline 27 & SUPA4 & 1 & - & - & - & - & - \\
\hline 28 & SUPA5 & 3 & + & + & - & - & - \\
\hline 29 & SUPA6 & 2 & + & + & - & - & - \\
\hline 30 & Gigante & 1 & - & - & - & - & - \\
\hline 31 & komboka & 2 & + & + & - & - & - \\
\hline 32 & Basmati370 & 2 & + & + & - & - & - \\
\hline 33 & WITA9 & 1 & - & - & - & - & - \\
\hline 34 & Supa Local & 2 & + & + & - & - & - \\
\hline 35 & AGRA41 & 3 & + & + & - & - & - \\
\hline 36 & AGRA60 & 3 & + & + & - & + & - \\
\hline 37 & AGRA65 & 1 & + & + & - & - & - \\
\hline 38 & NamChe1 & 2 & - & - & - & + & - \\
\hline
\end{tabular}


TABLE 5. Contd.

\begin{tabular}{|c|c|c|c|c|c|c|c|}
\hline \multirow[t]{3}{*}{ Entry no. } & \multirow[t]{3}{*}{ Accession } & \multirow{3}{*}{$\begin{array}{r}\text { Aroma } \\
\text { status }\end{array}$} & \multicolumn{5}{|c|}{ Functional markers } \\
\hline & & & ASA & $\begin{array}{l}\text { FMBADH2 } \\
\text {-E7 }\end{array}$ & $\begin{array}{l}\text { FMBADH2 } \\
\text {-E2A }\end{array}$ & $\begin{array}{l}\text { FMBADH2 } \\
\text {-E2B }\end{array}$ & $\begin{array}{l}\text { FMBADH2 } \\
-\mathrm{E} 4-5\end{array}$ \\
\hline & & & $\begin{array}{c}\text { 8bp } \\
\text { deletion }\end{array}$ & $\begin{array}{c}8 b p \\
\text { deletion }\end{array}$ & $\begin{array}{c}7 \mathrm{bp} \\
\text { deletion }\end{array}$ & $\begin{array}{l}\text { 7bp } \\
\text { deletion }\end{array}$ & $\begin{array}{c}803 \\
\text { deletion }\end{array}$ \\
\hline 39 & NamChe2 & 1 & - & - & - & + & - \\
\hline 40 & NamChe3 & 1 & - & - & - & - & - \\
\hline 41 & NamChe4 & 1 & - & - & - & - & - \\
\hline 42 & NamChe5 & 2 & - & - & - & + & - \\
\hline 43 & NamChe6 & 1 & - & - & - & - & - \\
\hline 44 & E20 & 1 & - & - & + & - & - \\
\hline 45 & E22 & 1 & - & - & - & - & - \\
\hline 46 & NERICA1 & 1 & - & - & - & + & - \\
\hline 47 & NERICA4 & 1 & - & - & - & + & - \\
\hline 48 & NERICA8 & 1 & - & - & - & - & - \\
\hline 49 & NERICA10 & 1 & - & - & - & + & - \\
\hline 50 & 1189 line & 1 & - & - & - & - & - \\
\hline 51 & 1190 line & 1 & - & - & - & - & - \\
\hline 52 & 1191 line & 1 & - & - & - & - & \\
\hline 53 & 326104 line & 1 & - & - & - & + & - \\
\hline 54 & Sande & 2 & + & + & - & + & - \\
\hline 55 & TXD306 & 1 & - & - & + & + & - \\
\hline 56 & Jaribu & 2 & + & - & - & - & - \\
\hline
\end{tabular}

$(+)=$ presence of deletion; $(-)=$ absence of deletion; $(-+)=$ heterozygotes using molecular marker method. $(1)=$ non-aromatic; $(2)=$ moderately aromatic and $(3)=$ highly aromatic using sensory evaluation

while seven accessions were found to be aromatic using this marker even after the sensory test scored them as non-aromatic.

There was no direct correlation between the badh2-E2 allele and aroma, based on the molecular marker data for these two primers, thus did not correlate with the sensory score. A Chi-square test of association between aroma and badh2-E2 allele was not significant (Chi-square=3.00; $P=0.2819$ ). Sequencing of the PCR product of these primers did not reveal a seven bp deletion in any accession.

FMBADH2-E4-5 indicated that all accessions were non-aromatic as none of the accessions carried the badh2-E4-5 allele.

\section{DISCUSSION}

Sensory evaluation revealed that 23 accessions were aromatic (Table 4); while 33 accessions were non-aromatic, and further subdivided the accessions into three distinct groups of accessions depending on the strength of the aroma perceived by the panelist (Table 4). This result is in agreement with Ocan et al. (2019) who also found differences in the strength of aroma among aromatic rice varieties. The strength of aroma is known to be influenced by cultivation condition such as temperature (Prodhan et al., 2017), Light intensity (Mo et al., 2015), plant nutrition (Lei et al., 2018) 


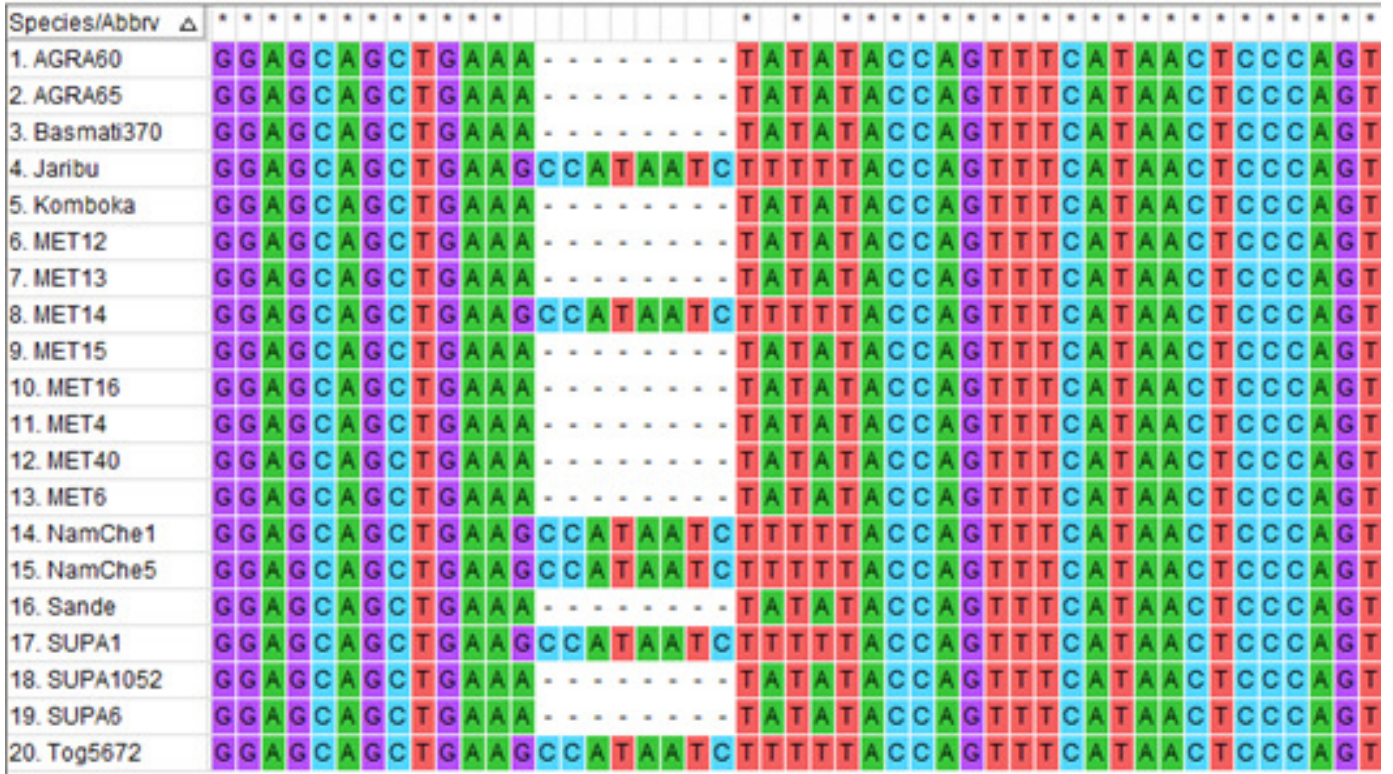

Figure 1. Sequence analysis showing the presence or absence of the $8 \mathrm{bp}$ deletion and three SNPs on exon two of the badh2 gene in selected accessions.

and soil salinity (Poonlapdechal et al., 2012). In the present study, there was no control for cultivation conditions; therefore variations in the strength of aroma is attributed to the genetic makeup of individual accessions.

There was no association between aroma and the ecology of the accession being either upland or lowland.

While 23 accessions were found to be aromatic using sensory evaluation, only 20 accessions were aromatic using molecular marker linked to the badh2 gene that confers aroma in rice. Four accessions (NamChe1, NamChe5, Jaribu and MET14) were scored as aromatic but did not contain the badh2-E7 allele characterised by an eight bp deletion and three SNPs. Two possible explanations; firstly, these accessions may have been scored as aromatic by mistake as each of those accessions were scored as aromatic by only one panelist. The ability to distinguish between aromatic and non-aromatic accessions diminishes with successive analysis either because the senses become saturated or the nasal passages may become damaged after inhaling $\mathrm{KOH}$ solution. Moreover, the ability to discriminate between samples varies between age, gender and cultural background.

Secondly, these findings indicate the presence of already reported or unknown mutations in a different part of the badh2 gene or in the promoter region (Bindusree et al., 2017). In order to obtain more conclusive results, we further evaluated the accessions using functional markers. The advantage of functional markers within the badh2 gene is that they permit direct selection of accessions that contain the gene that controls the aromatic phenotype, hence overcoming the limitations of sensory analysis. Molecular marker analysis, once combined with sensory methods, was able to represent the true aroma spectra of all the rice accessions in this study.

Twenty aromatic accessions had the badh2-E7 allele, characterised by an eight base pair deletion and three SNPs. A significant Chisquare test implies existence of a relationship between the badh2-E7 allele and aroma, thus confirming the genetic basis of aroma in these accessions that this allele is responsible for 
the aroma in theses accessions (Fitzgerald et al. 2008). The badh2-E7 allele is the most abundant allele in aromatic rice accessions, as nearly all aromatic rice accessions carry this allele (Bradbury et al. 2005a, Bourgis et al. 2008, Shoa et al. 2013, Bindusree et al. 2017). A whole genome sequencing of 76 aromatic accessions from the 3000 Rice Genome Project revealed the presence of badh2-E7 in 39 of the genotypes (Bindusree et al., 2017).

The 18 homozygous aromatic accessions for the badh2-E7 allele will breed true for aroma even in subsequent generations, making selection for the aroma trait more effective to conduct and thus are valuable resources for breeding and or be released as new aromatic varieties. The three heterozygous aromatic accessions confirm the existing genetic underpinning of the aroma trait in rice (Bradbury et al. 2005b).

\section{CONCLUSION}

Continuous increase in demand for aromatic rice in the global market has attracted attention of rice breeders to include grain aroma among the major breeding objectives for rice improvement. Sensory analysis combined with use of functional markers was able to accurately select twenty rice accessions that can be included as breeding materials for development of highly aromatic varieties. Other alleles were not reported in this study indicating the existence of a narrow genetic base for improving aroma among the germplasm collection. The number of accessions used in this study was low and may not be representative of the overall allelic diversity within the badh 2 gene.

\section{ACKNOWLEDGMENT}

This study was funded by the Deutscher Akademischer Austauschdienst (DAAD). NaCRRI provided the genetic material and Makerere University Agricultural Research Institute, Biotechnology laboratory hosted the molecular work.

\section{REFERENCES}

Amarawathi, Y., Singh, R., Singh, A., Singh, V., Mohapatra, T., Sharma, T. and Singh, N. 2007. Mapping of quantitative trait loci for basmati quality traits in rice (Oryza sativa L.). Molecular Breeding 21(1): 4965. doi:10.1007/s11032-007-9108-8

Andersen, J. and Lübberstedt, T. 2003. Functional markers in plants. Trends in Plant Science 8(11):554-560.

Asante D.M. 2017. Breeding rice for improved quality. Advances in International Rice Research. http://dx.doi:org/10.57721/ 66684

Bindusree, G., Natarajan, P., Kalva, S. and Madasamy, P. 2017. Whole genome sequencing of Oryza sativa L. cv. Seeragasamba identifies a new fragrance allele in rice. PLOS ONE 12(11): p.e0188920.

Bourgis, F., Guyot, R., Gherbi, H., Tailliez, E., Amabile, I., Salse, J., Lorieux, M., Delseny, M. and Ghesquière, A. 2008. Characterization of the major fragance gene from an aromatic japonica rice and analysis of its diversity in Asian cultivated rice. Theoretical and Applied Genetics 117(3): 353-368.

Bradbury, L., Henry, R., Jin, Q., Reinke, R. and Waters, D. 2005a. A perfect marker for fragrance genotyping in rice. Molecular Breeding 16(4):279-283.

Bradbury, L., Fitzgerald, T., Henry, R., Jin, Q. and Waters, D. 2005b. The gene for fragrance in rice. Plant Biotechnology Journal 3(3):363-370.

Bradbury, L., Gillies, S., Brushett, D., Waters, D. and Henry, R. 2008. Inactivation of an aminoaldehyde dehydrogenase is responsible for fragrance in rice. Plant Molecular Biology 68(4-5):439-449.

Calingacion, M., Laborte, A., Nelson, A., Resurreccion, A., Concepcion, J., Daygon, V., Mumm, R., Reinke, R., Dipti, S., Bassinello, P., Manful, J., Sophany, S., 
Lara, K., Bao, J., Xie, L., Loaiza, K., Elhissewy, A., Gayin, J., Sharma, N., Rajeswari, S., Manonmani, S., Rani, N., Kota, S., Indrasari, S., Habibi, F., Hosseini, M., Tavasoli, F., Suzuki, K., Umemoto, T., Boualaphanh, C., Lee, H., Hung, Y., Ramli, A., Aung, P., Ahmad, R., Wattoo, J., Bandonill, E., Romero, M., Brites, C., Hafeel, R., Lur, H., Cheaupun, K., Jongdee, S., Blanco, P., Bryant, R., Thi Lang, N., Hall, R. and Fitzgerald, M. 2014. Diversity of global rice markets and the science required for consumer-targeted rice breeding. PLoS ONE 9(1):e85106.

Diagne, M., Demont, M. and Ndour, M. 2017. What is the value of rice fragrance? Consumer evidence from Senegal. African Journal of Agricultural and Resource Economics 12(2):99-110.

Daygon, V.D., Calingacion, M., Forster, L.C., DeVoss, J.J., Schwartz, B.D., Ovenden, B., Alonso, D.E., McCouchs, S.R., Garson, M.J. and Fitzgerald, M.A. 2017. Metabolomics and genomics combine to unravel the pathway for the presence of fragrance in rice. Scientific Reports 7:112. https://doi.org/10.1038/s41598-01707693-9

Doyle, J. 1991. DNA protocols for plants. Molecular Techniques in Taxonomy. pp. 283 - 293. Doi: 10.1007/978-3-642-839627_18

Fitzgerald, M.A., Sackville-Hamilton, N.R., Calingacion, M.N., Verhoeven, H.A. and Butardo, V. Jr. 2008. Is there a second gene forfragrance in rice? Plant Biotechnology Journal 6(4):416-423. doi:10.1111/j.1467-7652.2008.00327.x.

Golestan Hashemi, F.S., Rafii, M.Y., Razi Ismail, M., Mohamed, M.T.M., Rahim, H.A., Latif, M.A. and Aslani, F. 2015. Opportunities of marker-assisted selection for rice fragrance through marker-trait association analysis of microsatellites and gene-based markers. Plant Biology 17(5): 953-961. https://doi.org/10.1111/plb.12335
He, Q., Yu, J., Kim, T-S., Cho, Y-H., Lee, Y-S. and Park, Y-J. 2015. Resequencing reveals different domestication rate for BADH1 and BADH2 in rice (Oryza sativa). PLoS ONE 10(8):e0134801. doi:10.1371/journal.pone. 0134801

He, Q. and Park, Y.J. 2015. Discovery of a novel fragrant allele and development of functional markers for fragrance in rice. Mol Breed 35:217. https://doi.org/ 10.1007/ s11032-015-0412-4

Hinge, V.R., Patil, H.B. and Nadaf, A.B. 2016. Aroma volatile analyses and 2AP characterization at various developmental stages in basmati and non-basmati scented rice (Oryza sativa L.) cultivars. Rice 9:122. Doi: 10.1186/s12284-016-0113-6.

Hollander, M. and Wolfe, D. 1973. Nonparametric statistical methods. New York: Wiley. Pages 139-146.

International Rice Research Institute. 2013. Standard Evaluation Systems for Rice. $5^{\text {th }}$ Edition. Manila, Philippines.

Kanaabi, M., Tusiime, G., Tukamuhabwa, P., Andaku, J., Ocan, D. and Jimmy, L. 2018. Evaluation of rice germplasm reveals sources of bacterial leaf streak disease resistance in Uganda. Journal of Food Security 6(4):163-169. https://doi.org/ 10.12691/jfs-6-4-4

Kovach, M.J., Mariafe, N., Calingacion, N., Melissa, A.F. and McCouch, S.R. 2009. The origin and evolution of fragrance in rice (Oryza sativa L.). ProcNatAcadSci USA 106:14444-14449

Kumar, S., Stecher, G. and Tamura, K. 2016. MEGA7: Molecular Evolutionary Genetics Analysis version 7.0 for bigger datasets. Molecular Biology and Evolution 33:1870-1874.

Lübberstedt, T., Zein, I., Andersen, J., Wenzel, G., Krützfeldt, B., Eder, J., Ouzunova, M. and Chun, S. 2005. Development and application of functional markers in maize. Euphytica 146(1-2):101-108.

Maraval, I., Sen, K., Agrebi, A., Menut, C., Morere, A., Boulanger, R., Gay, F., 
Mestres, C. and Gunata, Z. 2010. Quantification of 2-acetyl-1-pyrroline in rice by stable isotope dilution assay through headspace solid-phase microextraction coupled to gas chromatography-tandem mass spectrometry. Analytica Chimica Acta 675(2):148-155. doi: 10.1016/ j.aca.2010.07.024

Masette, M., Candia, A., Khakasa, E., Okurut, S. and Tinyiro, S.E. 2013. Preferences of Ugandan consumers for rice varieties and brands on the local market. Uganda Journal of Agricultural Sciences 14(2):111.

Mo, Z., Li W., Pan, S., Fitzgerald, T.L., Xiao, F., Tang, Y., Wang, Y., Duan, M., Tian, H. and Tang, X. 2015. Shading during the grain filling period increases 2-acetyl-1-pyrroline content in fragrant rice. Rice 8:9.

Ocan, D., Zhang, R., Odoch, M., Kanaabi, M., Ibanda, A.P, Akwero, A., Khizzah, B.W., Nuwamanya, E., Lamo, J., Fitzgerald, M. A., Daygon, V.D. and Rubaihayo, P.R. 2019. Relationship between 2-acetyl-1-pyrroline and aroma in Uganda rice populations with Oryza (barthi, glaberrima and sativa) backgrounds. African Journal of Biotechnology DOI: 10.5897/AJB2019.16960

Ootsuka, K., Takahashi, I., Tanaka, K., Itani, T., Tabuchi, H., Yoshihashi, T., Tonouchi, A. and Ishikawa, R. 2014. Genetic polymorphisms in Japanese fragrant landraces and novel fragrant allele domesticated in northern Japan. Breeding Science 64(2):115-124.

Poonlaphdecha, J., Maraval, I., Roques, S., Audebert, S., Boulanger, R., Bry, X. and Gunata, Z. 2012. Effect of timing and duration of salt treatment during growth of a fragrant rice variety on yield and 2acetyl-1-pyrroline, proline, and GABA levels. Journal of Agricultural and Food Chemistry 60:3824-3830
Prodhan, Z.H., Faruq, G., Taha, R.M. and Rashid, K.A. 2017. Agronomic, transcriptomic and metabolomic expression analysis of aroma gene (badh2) under different temperature regimes in rice. International Journal of Agriculture and Biology 19:569-576. https://doi.org/ 10.17957/IJAB/15.0340

R core Team. 2017. R Foundation for Statistical Computing, Viena, Austria.

Shao, G.N., Tang, A., Tang S.Q., Luo, J., Jiao, G.A., Wu, J.L. and Hu, P.S. 2011. A new deletion mutation of fragrant gene and the development of three molecular markers for fragrance in rice. Plant Breeding 130: 172-176.

Shi, W., Yang, Y., Chen, S. and Xu, M. 2008. Discovery of a new fragrance allele and the development of functional markers for the breeding of fragrant rice varieties. Molecular Breeding 22:185-192.

Shi, Y., Zhao, G., Xu, X., and Li, J. 2014. Discovery of a new fragrance allele and development of functional markers for identifying diverse fragrant genotypes in rice. Molecular Breeding 33:701-708.

Sood, B.G. and Siddiq, E.A. 1978. A rapid technique for scent determination in rice. Indian Journal of Genetics and Plant Breeding 38:268-271.

Varshney, R., Graner, A. and Sorrells, M. 2005. Genomics-assisted breeding for crop improvement. Trends in Plant Science 10(12):621-630.

Vemireddy, L.R., Satyavathi, V.V., Siddiq, E.A. and Nagaraju, J. 2015. Review of methods for the detection and quantification of adulteration of rice: Basmati as a case study. Journal of Food Science and Technology 52:3187-3202

Yeap, H., Faruq, G., Zakaria, H. and Harikrishna, J. 2013. The efficacy of molecular markers analysis with integration of sensory methods in detection of aroma in rice. The Scientific World Journal pp.16. 